\title{
Computer Use and Immersion in a Non-IT Course
}

\section{H. David Brecht, Suzanne M. Ogilby, and Eugene Sauls California State University, Sacramento, CA, USA}

\author{
brecht@csus.edu ogilbysm@csus.edu saulseh@csus.edu
}

\begin{abstract}
This paper presents an enhanced strategy to incorporate computer applications in a non-IT course, called Computer Immersion Strategy (CIS). Previous attempts to fully incorporate current technology in accounting courses highlighted the failure of those strategies to enable or motivate students to master analytical problem-solving skills. In response to this crucial shortcoming, CIS was developed for use in a numerically technical but non-IT course - cost accounting. The CIS strategy marries seven pedagogical and computer-use techniques to develop student analytical problem-solving: 1) sequencing of problem-solving techniques versus concepts, 2) increased complexity of problems solved by students, 3 ) in-class computer problems solved by students, 4) more convenient access to necessary course files, 5) interactive in-class assignments on the computer 6) course projects requiring the use of the computer, and 7) multi-media lectures made available through the course files.
\end{abstract}

Keywords: Education, innovation, pedagogy, courses, lectures.

\section{Introduction}

For several years, we have developed and augmented pedagogy that uses the computer to support lectures and problem-solving in the classroom and makes extensive lecture notes available to students for self-study. While the computer techniques used are unremarkable in the field of information technology (IT), their application is significantly innovative for a numerically technical but non-IT course - cost accounting. Our contributions have been to develop methods for applying computers in non-IT, routine daily instruction and to use the computer to empower students' self-study.

A summary of the issues involved, paraphrasing and quoting in part from Brecht, Sauls and Beirne, (2000) and from Brecht, Ogilby and Sauls, (2003) are provided below.

Many academic programs, including our accounting program, have experienced changing demographics for students, such as an increase in students who have English as a second language. Complete lecture files give these students the ability to re-experience and self-study lectures in the exact presentation sequence and with the same content as originally heard. This study can be done at an individual's own reading-comprehension pace and with the aid of dictionaries if needed. The premise for this benefit is that the instructor uses the same computer files to present the lecture.

Material published as part of this journal, either on-line or in print, is copyrighted by Informing Science. Permission to make digital or paper copy of part or all of these works for personal or classroom use is granted without fee provided that the copies are not made or distributed for profit or commercial advantage AND that copies 1) bear this notice in full and 2) give the full citation on the first page. It is permissible to abstract these works so long as credit is given. To copy in all other cases or to republish or to post on a server or to redistribute to lists requires specific permission from the publisher at Publisher@InformingScience.org
Complete lecture files also benefit students with deficiencies in educational backgrounds, including lack of prior exposure to topics in core courses or the need to study prerequisite topics on a remedial level. 
An increasing number of students work part or full time. Especially for night classes, these students are likely to be tired, and find intense concentration and retention difficult. Complete lecture files allow them to get a lighter overview and familiarization with topics during class and intensively self-study the entire lecture content on weekends or as study time becomes available.

Although none of the authors has class-tested these computer-use methods in a web-based course, it appears reasonable to expect that we have developed a way to lecture over the internet. Complete lecture files can be delivered to students and can be printed by them before a class session. When combined with streaming audio and other online student-instructor interaction capabilities, students can participate at a high interaction level in the online session. Class session content is not delayed by students' capabilities to take notes during the online session. Students can prestudy the lecture's content to support more targeted questions and interaction. Moreover, an instructor's choice of topic content is substantially freed from a textbook as the only efficient and feasible way to transfer a large body of content.

The pedagogy and computer-use techniques we presented in our earlier papers were class tested in required undergraduate cost-accounting classes over more than two years. The Computer Immersion Strategy (CIS) - presented in this paper - is being class tested in the Fall 2003 in an elective management accounting course. This repeated class testing strengthens our understanding and evaluation of the pedagogy and techniques' success. However, we have been significantly evolving computer-use methodology so rapidly that while we have conducted results-oriented surveys, we have yet to statistically test our pedagogy and techniques' success. Our evaluation of this previous pedagogy and techniques' success, limitations, and difficulties is presented in the next section of the paper.

Initially conceived to resolve failings we found with the previous pedagogy and techniques, we extend the above types of innovation to a Computer Immersion Strategy (CIS). Our CIS requires a classroom with a computer at every student's desk and engages students with the computer interactively in class as well as at home. As much as is possible, daily and throughout the course, the computer is used by students as well as the instructor. This involvement includes lectures, homework, exams, projects, and course housekeeping procedures. We discuss CIS in the last section of the paper.

\section{Evaluation of Previous Pedagogy and Techniques}

The "results" failing of our previous designs for computer assisted instruction and student selfstudy is that too many students did not learn or improve their ability to solve difficult problems. Repeatedly, over several semesters, toward the end of the semester, $60-80 \%$ of students on a difficult exam problem would make dismal grades. They had successfully learned concepts - as demonstrated on true-false and multiple choice questions. And they had successfully learned analytic methods applied in solving quantitative problems - as demonstrated by making high grades on easier problems that were similar to or only mildly varied from what they had seen before in class. But they had weak skills in facing a blank piece of paper on exam day; reading and comprehending a new, more difficult problem; structuring the data and problem solution, i.e. getting the data out of the problem and into an analytic structure with which they in fact were familiar; and solving significant portions of the problem, if not the entire problem.

So we deduced that our previous pedagogy and computer-use techniques did not support teaching critical thinking or problem solving at a sufficiently high level. Prior computer-use innovations did improve student interest in the class, the volume of concepts and problem types that can be delivered in the time available for a course (in particular, class time), and successful student learning of concepts and problem types. But there is the critical exception of not teaching significantly difficult problem solving. 
We evaluated the elements of our previously developed pedagogy and computer-use techniques from the perspective of how they failed to develop significant problem solving abilities. As described in the next section of the paper, we address these failings within our computer immersion strategy. Although it may not be obvious as you read the failings we identify, we think the computer does have a central role in correcting these failures.

We teach accounting - a technical subject that might be described as complex arithmetic (quantitative problem solving) with a lot of rules and underlying concepts. Our previous pedagogy often separated concepts from arithmetic, the idea being that students need to learn how to think about the subject and, separately, how to make arithmetic calculations relevant to that subject. In effect, our study approach and structuring of the class notes was from the perspective of a manager who, if needed, could make relevant computations - call it, if you will, a graduate school of management approach.

Our failing was that we assessed the students' problem solving abilities too highly. Many of our students are not well trained or naturally capable in mathematical problem solving. Their technical (quantitative) training does not appear to attain certain minimum benchmarks of success. These benchmarks are made clear by existing national certification exams, such as the Certified Public Accounting exam.

Somewhat in connection to the above ("1.") dual emphasis on problem solving and concepts, we used a preponderance of low to moderate difficulty homework problems. Students found that they could understand and have a sense of having learned the analytic methods by reviewing the problems' solutions in the summary file provided for each chapter. However, many students did not work through the interactive problem-solving files that were included with the course files.

Several other features of our computer-use design led students to avoid working with the interactive problem-solving files that were available. These files are designed to walk students through problems, offer solution comments, teach problem solving techniques, and build quantitative analysis skills.

Also, the course files contained a summary file for each chapter into which the content of all the various files used in the lectures for that chapter had been cut and pasted. This enabled a singlefile print out of all materials for the chapter - intended as a convenience for self-study and review. Inadvertently, the summary file helped students avoid using the computer with the interactive problem-solving files and made it easy for them to rely on the single-file printout. Thus, they did not perform the file-based work on the computer that is designed to build problem-solving skills.

The course files were obtainable either over the internet or by writing a CD with the necessary files. Students found it easier to download the summary files from the web than either (a) download many files over the web (the course files' size totals about 42 megabytes) or (b) undergo the learning and relative inconvenience necessary to get, write, and use CDs. For many students, the computer became a single-file delivery and printout mechanism rather than a multi-file tool that adds value to self-study and the development of problem-solving skills.

Finally, we think that omitting certain elements from previous pedagogy and computer-use designs worked negatively to make it easier for students to avoid using the computer as a study and learning tool. We think that the use of computers to teach problem solving techniques and build quantitative analysis skills is ineffective for those students who have no desire to learn them or use the computer. Stated a little differently, we think that for many of our students, computer-use innovation is ineffective if the computer is not fully integrated into the student's course experience. Its use needs to be an aspect of everyday expectation and reality to fully contribute to a student's learning potential. 
We identified three areas where we did not previously or consistently use the computer to achieve student learning goals: (a) frequent in-class assignments that require students to use the computer while in class, (b) projects requiring use of the computer both in class and at home, and (c) multimedia lectures in class to create learning variety and stimulate a greater depth of interest in the subject.

\section{Computer Immersion Strategy}

We understand many of the issues involved with teaching in-depth thinking and problem solving: students' ability, motivation, prior training, and time needed to develop abilities and interest. But these issues exist as an environment for a particular course. The question at issue for us is: "Can the computer be used to successfully teach critical thinking or problem solving at a sufficiently high level - given the environment?"

We think there are learning benefits if students continually use the computer with innovative pedagogy and applications - all accomplishable in technical, non-IT courses. The learning focus is not to study IT methods or tools, but to use these tools to study other subjects (accounting in our case). We think the use of computers should not be limited to IT courses, to enabling PowerPoint for classroom lectures, or to requiring student involvement in an occasional course project. Rather, computers should be used as a fundamental and pervasive tool that supports learning (of non-IT topics and skills) - what we call a "Computer Immersion Strategy" (CIS).

\section{Technical Issues}

First, there are some technical constraints to address. Our CIS assumes that the university has, or is acquiring, the necessary facilities. Technical capabilities that we have needed and used are listed below although support needs vary from course to course.

A sufficiently large classroom with a computer on each student's and the instructor's desk. "Sufficiently large" means satisfying administration demands for a minimum class size.

A server linked to the classroom computers with sufficiently large data transfer rates and processing abilities. The server must be appropriately configured and the wiring between the server and student and instructor computers must have sufficiently high transfer rates to support real-time data and graphics transfers between all computers. A dedicated server and fiber optics appears to be one "ideal" configuration.

Appropriate server configuration means that both students and the instructor can transfer files to and from the server with appropriate passwords unique to the instructor and the course. The instructor has sole permission to read/write all course folders as well as have administrative rights to and ownership of the course folders. Students can log on with their password and read files from a "pickup" folder. By next year our students will be able to write, but not read, files to/from a "deposit" folder. More is said below on how this design is used.

A Writable CD drive and sufficient software, power, and memory on each classroom computer. The course files, where we are class-testing CIS, have a total size of about 116 megabytes. This requires a writable CD drive because students generally do not have ZIP drives on their home computers. Students should use high quality, rewritable CDs.

The software that should be on all classroom computers is: Microsoft Office (Excel, Word, PowerPoint, Internet Explorer), Apple's QuickTime for Windows, and Microsoft Producer. More is said below on how this software is used. Additionally, we use Altiris' Vision 4.1 - a program that allows the instructor to monitor and interact with students' computers and that allows any computer's screen to be displayed on the screen at the front of the room. Finally, each computer is configured with Faronics' DeepFreeze - a program that rewrites a computer's disk on each 
boot and provides security for Windows. This enables users to introduce executable programs to their computers without transferring any viruses or other damage to future users or the computer's permanent files.

At any time, a computer may be running several programs - Vision, Excel, PowerPoint, IE, and even QuickTime. Therefore, there is a need for significant power and memory (ram and disk storage).

An IT staff, administration, and faculty that can and want to resolve these difficulties. This of course requires time and resources from all parties concerned. We are fortunate to have a business school accrediting organization (the AACSB) and other parties that "make it happen". There are the dynamics involved with pushing beyond what already exists and is in place. We have experienced some start-up delays on a few needed elements.

\section{Pedagogy and Computer-Use Techniques}

There are seven elements in our "Computer Immersion Strategy," the central goal being to teach students to solve new and difficult problems without sacrificing conceptual content.

The instructor class-testing CIS had previously organized course lectures and files so that concepts were separated from calculations. The goal was to focus on thinking about a business problem, formulate the problem's information requirements and issues involving information use, and then execute quantitative analyses to provide the needed data. Quantitative problem-solving was fit within a business context.

Computer Immersion Strategy with an emphasis on developing problem-solving skills reverses this analysis process. The priority becomes upgrading students' quantitative technical competence. Concepts are taught in the context of technical problems. To accomplish this, the assigned problems must be very good, supporting both quantitative analysis and relevant conceptual development. Thus, the instructor class-testing CIS first changed the course adoption to a textbook that is known for its quantitatively rigorous and conceptually fertile problem assignments. The instructor wrote all new lectures, not to diminish concept, but to restructure them underneath and in support of the chosen problems' analysis requirements. An example of an initial Excel file with concepts embedded as second layers of information (accessed through links) is shown in Appen$\operatorname{dix}$ A.

Previously, Word (doc) and HTML files were predominant and initiated a topic's coverage. Technical calculations were in Excel files linked to/from the text files. Concepts were considered first, and technical material had a supporting role. Under CIS with a quantitative skills priority, Excel files are used with all the elements associated with a quantitative problem's structuring, analysis, and solution. The Excel files and problem focus initiate thinking about the topic. Then concepts are linked to/from the flow of reasoning about the problem. links are to Word (doc), HTML, PowerPoint (ppt), and video files (mov).

The student learns much the same material as before, but not from the same sequence of reasoning and topic development. We think this approach will better meet our students' need for improved quantitative-analysis skills.

We believe that an aspect of the above computer use is particularly interesting from an IT perspective. The method of using computers in the classroom has both broad and nuanced pedagogical implications. Computer use can be adapted for different pedagogies and different student populations.

In our application, students are working with more complex and difficult problems. There are likely to be learning difficulties if students merely print the content of various files for a problem 
and try to develop problem-solving competence by reading the solution. Thus, we eliminated "summary" files where we had collected all the content of other files for students to print out and study. To some extent, we eliminated student convenience to encourage more student involvement and thinking.

Our focus became choosing problems and designing their structure to "force" students to study a problem's solution with the result that their problem-solving competencies are increased. Also, in a previous design, we gave students formatted templates that exploited Excel's features (e.g. comments, conditional if-statements, etc.). Students were to work through the file, entering calculations and developing the problem's solution. A second file was given that had the correct solution worked out in the template's format. We found that many students skipped over the blank template and merely read the solution file. A result is they did not learn analysis - perhaps due to their own laziness - and could not solve difficult problems on exams.

First, we changed our pedagogy by using problems that are sufficiently difficult to force study and intellectual engagement. Second, we believe that IT can be used, and is likely to be necessary, to empower learning - especially when done at home in self-study. Files given to students are designed to move a student's reasoning and study along a path that mirrors the reasoning and discovery an instructor would deliver in a lecture. It is not the exploitation of a unique feature of Excel that empowers learning, although software features can be used as elements in the problemsolving structure. It is a computer file that that is pedagogically structured that empowers learning. We use a file's information capacity (far beyond what an instructor has time to write on the board in class) to enable extensive and interconnected topic development. It is the canvas of a computer file that enables a type of topic development that empowers self-study and learning. Again, see Appendix A for an example of an initial Excel file in a section of study.

Student study of the topic development and problem-solving files discussed in "2." above is reinforced by in-class assignments (ICA). Students have an in-class assignment where they download a difficult problem to their computers. The problem has analysis and solution characteristics that are at the level of challenge in the course lecture files for that topic. This in-class assignment is open notes, including the course files. The intent is to directly reward self-study of the notes and the development of an ability to use the relevant course problem files. Each ICA is graded as a small exam and counts about $5 \%$ of a student's course grade.

Students download the ICA from the course's "pickup" directory (on the classroom server). This is an Excel file, and students must solve the problem on the file and save it to a "deposit" folder. As said above in "Technical Issues", this folder (write-only, no overwrite of a file already saved, and no read permission) is not currently operational, but will be in the next academic year. Currently, students email a copy of their solution Excel file to the instructor and, for backup, provide a copy on a $3 \frac{1}{2}$ " disk.

We eliminated the internet as a means of working with course files, although the course syllabus, grade book, and bulletin board are still accessed on the web. Course files are now available only through a disk medium (e.g., by copying the course files to a CD). This change was necessary because of the 116 megabytes size of the course files. This change also avoids the time consuming, discouraging aspects of a dial-up internet connection (slow data transfers and being dropped from the connection by the internet service provider). Now a student can bring up any course file and study it on his/her computer, avoiding any internet constraint.

A pedagogical issue is how to design assignments that require students to use the computer while in class, other than the ICA, on a routine basis. The goal is not just to bring computer use into the classroom, but to create examples of analysis that are taken home and studied. That is, how does one make self-study stay true to the sequence of reasoning and topic development embedded in the course's problem files? Can in-class computer use be designed so that self-study becomes a 
natural extension of what is done in class and stays true to the analytic structure developed in the files? The benefit to students is conditional on the files' pedagogical design - they must support and improve learning.

The in-class assignments (ICA) in "3." above are a step in this direction and illustrate the goal. They are designed to reinforce students' adherence to the problem and solution structures in the course files. They place a premium on being familiar with using the course files both for the analytic method and for the flow of problem-solving reasoning and analysis. However, more work is needed to make in-class study using the computer routine.

Another approach requires developing an interactive, question-answer method in the medium of computer files. For example, the formatted template files that we referred to in " 2 ." above may be redesigned so that each student can parallel the solution the instructor is developing in the lecture, but in the student's file on his/her local computer. At appropriate points, the instructor can ask the students to independently solve a section of the overall solution and save the file to the "deposit" folder. This material would be graded and factored into the students' course grades.

For conceptual interaction, lecture points might be developed in Adobe Acrobat (pdf) files that are, in part, fillable forms. Students could be asked to answer certain questions with short answers, and save the file to the "deposit" folder. A drawback is that a site license for a standard version of the Adobe software would be required; but a benefit is the ability to structure the length of answers allowed, i.e. force short and tightly formatted answers. Benefits of both the quantitative and conceptual in-class applications are (a) students are encouraged to prepare for class and to prepare using the course files, (b) students have the grade incentive of staying engaged with the lecture and closely following the reasoning and topic development of the files being discussed, and (c) students are positively motivated through the interactive process (i.e., the fun of the interactive "game").

Course projects requiring use of the computer are not new. They involve students using computers both in class for instructional purposes and at home to execute and complete the project. In a sense, they are the icing on the pedagogical cake. That is, students use both analytic and computer skills to solve a large problem. Our students report enjoying our course projects and getting a sense of having learned a lot. We briefly present the two projects, not that using projects is special, but to show the type of computer-interactive projects we use.

One project involves using Excel's regression and correlation analysis tools to solve a cost accounting case (involving $52 \times 15$ data values). Because of its size, the problem can only be solved efficiently using the computer. Its solution does not just use an algorithm that produces an answer, but requires analytical reasoning. Solving the case involves (i) a lot of conceptually directed selecting, disregarding, and moving about of sample data in Excel spreadsheets and (ii) the evaluation of regression solutions.

The overarching analysis and solution process is one of students conceptualizing an analysis with sought-after solution characteristics, organizing data for the analysis, using Excel's analysis tools to generate a solution, evaluating the solution, and then repeating the process until a satisfactory solution is found. The learning objective emphasized is not how to use the software. Excel is not used as a "best" analysis tool, but as a desktop tool that is readily available and easily learned and used. The learning objectives are focused on the accounting case application. But analysis and solution are only feasible on the computer, and the solution process is highly interactive and gratifying to students. About one class week is dedicated to this project; and it was developed by the instructor teaching the course.

The second project involves a CD-based case simulation that costs about \$25 U.S., but has the quality and variety of interactive features that suggest a much greater cost. The CD simulation 
involves built-in briefing information that can be studied, decisions that can be entered and run as game values that compete in a competitive environment across time, video and audio responses to the decision values entered and the game results to which they lead, and tutorials that respond to the decision values entered. This simulation exceeds all the project features and objectives we seek and those described in "(a)" above. About two class weeks are dedicated to this project; and it is the final, capstone project for the course. Again, analysis and solution are only feasible on the computer, and the solution process is extremely interactive and highly gratifying to students. The product is: Balancing the Corporate Scorecard 2.0 - An Interactive Simulation, Kaplan and Norton, Harvard Business School Publishing and High Performance Systems. Appendix B contains a picture of the interface through which students make decisions and run the simulation.

Multi-media lectures are also not new - we just accomplish them with desktop software and make them available to students through the course files. We use multiple media in the classroom to add variety and create interest. Multi-media add an element of fun to delivery, and can be reexperienced by students at home in self-study. We use, for different purposes, in varying combinations, and with varying frequency: Excel files (xls), Word files (doc), HTML files (viewed in Word, Excel, or Internet Explorer - as useful or appropriate), PowerPoint files (ppt), video files (mov and viewed in QuickTime), and the CD-simulation project files (itm and viewed in QuickTime).

For lecture material not otherwise well-supported by the course files, we use Microsoft Producer to create audio copies of lectures. One such set of files, about 20-40 megabytes in size, can be accessed and heard through Internet Explorer and Windows Media Player. Students copy the files to their CD from the classroom server "pickup" folder and use them for self-study at home.

\section{Lessons Learned about Using CIS as A Pedagogical Tool}

Our "lessons learned" are based on the results of class testing CIS in a one semester, Cost Accounting course. Our observations are divided into two segments: (a) student performance in learning and perception of the pedagogical tools used and (b) student enjoyment of the instructorstudent interaction.

Regarding learning, CIS was successful. Average grades for each segment of the course were as follows: a regression analysis project (86\%); an accounting information and management decision-making simulation (95\%); in-class assignments and homework/lecture exams (81\%); and midterm exams (73\%). Student performance on computer-based work areas (the first three areas) was higher than performance on handwritten midterm exams. It appears that interaction with the computer was successful in keeping students engaged with the topics studied and tasks required.

The drop off of performance on the midterm exams is probably not computer related, but a result of a large amount of material being examined with difficult problems and questions. Students often commented during the semester about the value of the course and the large amount of information they were learning. Most of the students appeared enthusiastic about the course topics and computer use from the beginning of the course through the major simulation project in the course's last two weeks.

The students' enjoyment of the instructor-student interaction was generally bi-modal and less favorable than their enjoyment of the exercises. Although understanding the cause of this result is confounded by a factor other than the CIS strategy (the instructor experienced a death in his immediate family one month before classes began), we think there are valuable pedagogical lessons to be learned in this area. 
We think an instructor can neither lecture nor conduct an on-campus class "through the computer" with success for all students. We use the phrase "through the computer" with special meaning. It is likely that the instructor in this instance was to some degree emotionally withdrawn and fell into teaching "through the computer" - a practice that can substantially divert an instructor's attention from the students. The instructor becomes more involved with the computer than with the students, and the students experience the classroom interaction as such. This diversion can reduce the instructor's ability to establish a warm, "coaching" rapport with the students that builds their excitement for the class session. We hypothesize that not all students will find the computer so interesting that their enjoyment of a class session can survive a reduction (or loss) of the human element between an instructor and students.

For contrasting examples, suppose an instructor is using PowerPoint to give a lecture. The task of progressing through slides is so simple and transparent that the instructor can fully engage the class in an exchange of personalities as well as topic content while clicking the slide progression forward.

Alternatively, suppose the instructor is solving a problem by making analytic-structure, formula, and data entries in an Excel spreadsheet that the students can view on their desktops or a projection on the classroom screen. Some - not all - students may need the contact or warmth of "close" human engagement to stay interested, be motivated, and enjoy the class session. The instructor's engagement with the computer seems to be experienced by some students as detachment - putting them outside of the lecture relationship and class discussion. These students lose the human element they need.

For future development of the CIS pedagogy, it seems clear that the instructor must stay focused on being engaged with the students. However, there is a point at which the instructor would seemingly have to work with the computer at the expense of personal engagement with the class. Pedagogical fine-tuning of the use of the computer may alleviate this problem, for example making greater use of macros. This is an area for future development. It is also worth noting, although not a subject of this paper, that these issues may have implications for a "best" way to offer web courses. It may be that a streaming video web course is "best" for substantial pedagogical reasons, streaming audio is second best, and a keyboard-only pedagogy is least preferred.

\section{Conclusion}

The development of pedagogical techniques that exploit the ever increasingly sophisticated computer and software capabilities can be deceptively simple. On the one hand, the computer provides greater opportunities for instructors and students to experiment with new and more efficient means of imparting, receiving, and analyzing information. On the other hand, the computer may allow students to skip essential exercises designed to enhance their analytical problem solving techniques - a problem with most pedagogical techniques. The students then resort to typical exam-passing strategies such as memorization. The Computer Immersion Strategy (CIS) attempts to design a pedagogical process, with the computer as the central focus point in that process, that eliminates student circumvention of techniques designed to enhance their analytical capabilities.

The computer immersion strategy extensively uses more complex in-class problems that each student solves on the computer, independently and/or interactively as part of class time. We believe CIS is a step toward prevention of lazy self-study techniques used in our previous attempts to develop a computer-oriented pedagogy. The reordering of problem-solving versus concept sequencing and the use of multi-media highlight our recognition that the principal responsibility for keeping students engaged in the learning process lies with the instructor. 


\section{References}

Brecht, H.D., Sauls, E., \& Beirne, T.J. (2000). Context enriched spreadsheets: A tool for addressing pedagogical dilemmas posed by bi-polar student characteristics. WSDI 2000 - Maui Proceedings.

Brecht, H.D., Ogilby, S.M., \& Sauls, E. (2003). Self-study interactive lectures. Informing Science + IT Education Conference 2003 - Finland Proceedings.

\section{Appendix A Abbreviated Lecture File}

\section{Problem 5-29, 30, 31 \\ 1.1. Begin by looking through the problem \& requirements to identify the basic solution model(s) needed and any other requirements.}

a. Outline the basic costing model(s).

1. P5-29's Part 2 asks for costs allocated to customers using the existing costing system. In the setup, paragraph 3 , there is a single cost pool and cost driver.

\begin{tabular}{|c|l|l|l|l|l|l|}
\hline $\begin{array}{c}\text { underlying } \\
\text { concepts } \\
\text { LINK }\end{array}$ & & & & & & \\
\hline b. Identify any other requirements. & & & & & & \\
\hline
\end{tabular}

1. P5-29, part 1: "why is it important to understand costs associated with different customers (jobs)". The key idea is in paragraph 3's line 1: prices charged customers.

\begin{tabular}{c|c}
$\begin{array}{c}\text { underlying } \\
\text { concepts } \\
\text { LINK }\end{array}$ & Return to "2.1". \\
LINK
\end{tabular}

2.

P5-31, part 2: Part 2 asks what actions managers can take or improve upon by having more accurate customer costs.

\begin{tabular}{|c|c|c|c|c|c|c|c|}
\hline & \multicolumn{2}{|c|}{$\begin{array}{c}\text { 1.2. Solve P5-29 } \\
\text { Part } 2\end{array}$} & \multicolumn{3}{|c|}{$\begin{array}{l}\text { 1.3. Solve P5-30, } \\
\text { Parts } 1 \& 2\end{array}$} & \multicolumn{2}{|c|}{$\begin{array}{l}\text { 1.4. Solve } \\
\text { Part } 1\end{array}$} \\
\hline & $\begin{array}{l}\text { Wid } \\
\text { nes }\end{array}$ & $\begin{array}{l}\text { St. } \\
\text { Mel }\end{array}$ & $\begin{array}{l}\text { Wid } \\
\text { nes }\end{array}$ & $\begin{array}{l}\text { St. } \\
\text { Mel }\end{array}$ & & $\begin{array}{l}\text { Wid } \\
\text { nes }\end{array}$ & $\begin{array}{l}\text { St. } \\
\text { Mel }\end{array}$ \\
\hline$\underline{\text { Direct Costs }}$ & \multicolumn{2}{|c|}{$\begin{array}{c}\text { a. } \\
\text { underlying } \\
\text { concepts LINK }\end{array}$} & & & \multicolumn{3}{|c|}{$\begin{array}{c}\text { a. } \\
\text { underlying } \\
\text { concepts LINK }\end{array}$} \\
\hline professional labor & & $\$ 6,720$ & $\$ 7,280$ & $\$ 6,720$ & & \multicolumn{2}{|c|}{$\$ 2,400 \$ 5,600$} \\
\hline partners labor & & & & & & 4,000 & 2,000 \\
\hline \multicolumn{8}{|l|}{ associates labor } \\
\hline research support & & & 1,600 & 3,400 & & 1,600 & 3,400 \\
\hline computer time & & & 500 & 1,300 & & 500 & 1,300 \\
\hline
\end{tabular}




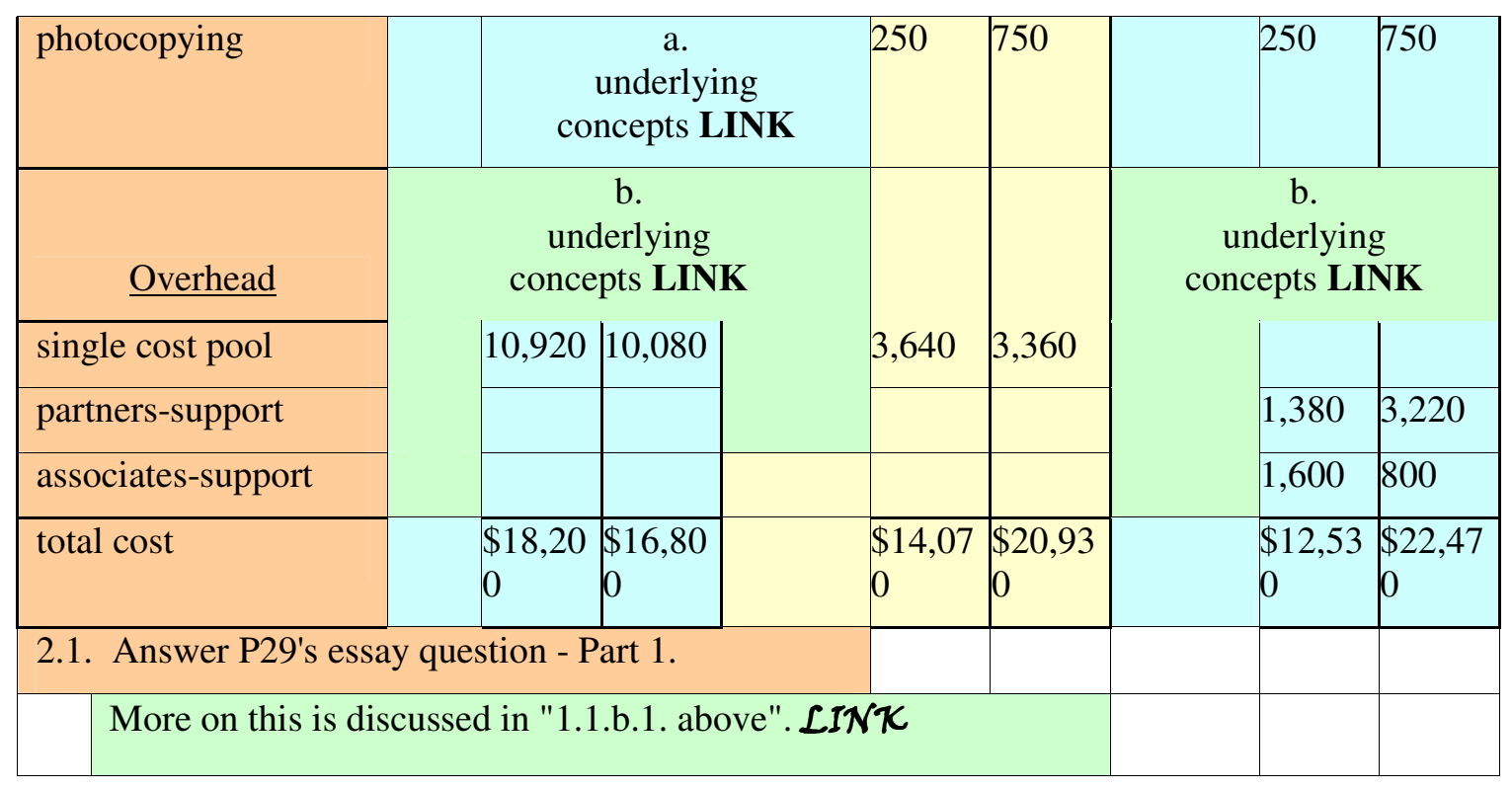

\section{Appendix B Harvard Simulation Interface}

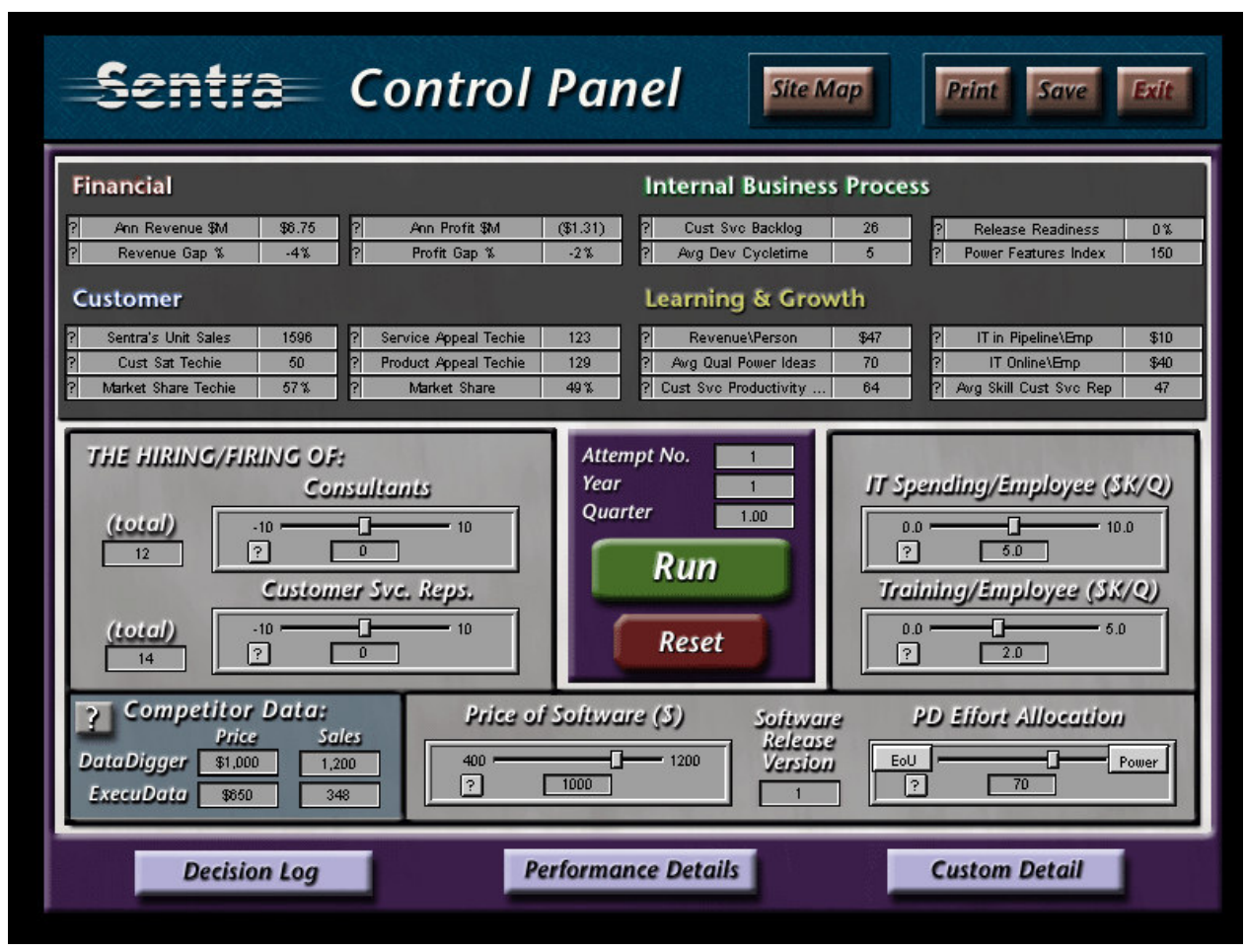




\section{Biographies}

H. David Brecht holds a PhD from the University of Texas at Austin. He joined the faculty at CSUS in 1975 and has an extensive publication record, principally in the area of cost/managerial accounting. His teaching areas have included auditing, systems, and cost/managerial accounting.

Suzanne M. Ogilby holds a PhD from the University of Wisconsin. She joined the faculty at CSUS in 1990 and has an extensive publication record, principally in the area of financial accounting. Her teaching area is financial accounting. She serves as the Chair of the Department of Accountancy and is the Gini and Macias Research Faculty recipient.

Eugene Sauls holds a PhD from Michigan State University. He joined the faculty at CSUS in 1984 and has served as Department Chair and Associate Dean of the College of Business. His principal teaching area is cost/managerial accounting. 